\title{
LAS DISCONTINUIDADES ENTRE LA MEMORIA COLECTIVA Y LA HISTORIA: UNA CRÍTICA A PARTIR DE LA EXPERIENCIA DEL HOLOCAUSTO
}

\section{THE DISCONTINUITIES BETWEEN COLLECTIVE MEMORY AND HISTORY: A CRITIQUE BASED ON THE HOLOCAUST EXPERIENCE}

\author{
Rafael Pérez Baquero ${ }^{1}$ \\ Universidad de Murcia
}

Recibido: 20/06/2016

Aprobado: 03/02/2017

\begin{abstract}
Resumen: El sociólogo francés Maurice Halbwachs fue el pionero en la justificación y desarrollo de la categoría "memoria colectiva", como mecanismo a través del cual los grupos humanos interactúan con su pasado. No sólo ofreció una descripción de este concepto, sino que también expuso su relación con el discurso histórico. Construyó un modelo en el que ambos se caracterizaban por sus diferencias y discontinuidades. En las siguientes páginas expongo las líneas de este marco teórico y cuestiono sus presupuestos en base a tres argumentos que giran en torno a los desafíos que suscita la recepción del Holocausto a la representación histórica.
\end{abstract}

Palabras clave: Memoria colectiva; historia; Holocausto; testimonio; escritura.

\begin{abstract}
The French sociologist Maurice Halbwachs was the first one who justified and developed the notion of "collective memory", understood as a tool though which human groups interact with their past. He also described the relation between collective memory and historical discourse. He defended some theses that emphasize their discontinuities and differences. In the following pages I will present the features of his theses and I will critique his assumptions. My critique will be based on arguments that revolve around the challenges that came from the historical reception of the Holocaust.
\end{abstract}

Key-words: Collective memory; history; Holocaust; testimony; writing.

1. (rafaelperbaq@gmail.com) A partir del curso 2014/2015 realizó un doctorado en el Programa de doctorado de la Facultad de Filosofía de la Universidad de Murcia. El título de la tesis es "De la memoria histórica al deber de la memoria". Es dirigida por Antonio Campillo Meseguer y Jorge Novella Suárez. Anteriormente ha disfrutado de las siguientes becas y ayudas de investigación.Beca de colaboración Universidad de Murcia. Departamento de Filosofía. Financiada por el MECD. Ayuda de iniciación a la investigación Universidad de Murcia, Murcia (España) Proyecto a desarrollar: "La proyección de la filosofía de la historia en Walter Benjamin (la filosofía de la historia en W. Benjamin y su recepción en el pensamiento español)" 


\section{Introducción. La historia frente "al pasado que no pasa"}

Desde que en 1924, Maurice Halbwachs desarrolló sus estudios en torno al concepto de la memoria colectiva, este objeto ha sido ampliamente analizado en el campo de la sociología y de la teoría cultural. Al fin y al cabo, constituía un recurso para dar cuenta de los mecanismos a través de los cuales los grupos humanos interiorizaban e interpretaban su pasado, como prisma para articular y dar sentido a sus prácticas y experiencias presentes. La memoria, al funcionar como el eje de una continuidad narrativa de recuerdos compartidos, sirve como principio de identidad colectiva.

Ahora bien, algunos acontecimientos ocurridos en el pasado siglo han atraído la atención respecto a la potencial aplicación de este concepto al campo de la teoría de la historiografía, al ámbito de los problemas relativos a los procesos de escritura de la historia, a finales del siglo XX. El binomio historia-memoria, como estudio de los límites y la permeabilidad de la frontera entre ambas formas de relación con el pasado, se popularizó precisamente a partir de la aparición de fenómenos históricos que cuestionaban los límites existentes entre los procesos de escritura de la historia y los factores ético-políticos que subyacen a los mismos.

Al fin y al cabo, la memoria constituiría el anclaje de la historia a factores contextuales, por lo que posicionarnos en torno a la interacción o discontinuidad entre estas categorías tiene amplias consecuencias para nuestra comprensión de la conciencia histórica. Varios historiadores, entre los que podemos destacar a Enzo Traverso ${ }^{2}$, Dominick LaCapra ${ }^{3}$ o Jay Martin ${ }^{4}$, han defendido que el estudio acerca de esta relación tiene un enorme potencial para explicar algunos conflictos que subyacen a la labor del historiador en el pasado siglo. Por ejemplo, el debate de los historiadores alemanes en torno a la singularidad del Holocausto, el negacionismo de los crímenes armenios por parte del imperio turco, los conflictos en la interpretación sobre las causas y factores del fascismo...

En este ensayo haremos referencia concreta al Holocausto, como eje para aplicar estas categorías, por varias razones. En primera instancia, por haber sido objeto de una construcción retrospectiva que, motivada por factores sociales, políticos y culturales, lo ha convertido en el paradigma de la violencia genocida del siglo XX. Por sus propias características y por las peculiaridades de su recepción historiográfica, se ha transformado en el icono de la memoria de los crímenes del pasado siglo, que constituye

1. Traverso, E.: El pasado, instrucciones de uso: historia, memoria, política, Madrid: Marcel Pons, 2007.

2. LaCapra, D.: Representar el Holocausto, Buenos Aires: Prometeo libros, 2008

3. Winter, J.: Remembering War, New Haven \& London: Yale University Press, 2006.

Thémata. Revista de Filosofía №56 (2017) pp.: 41-60. 
la imagen negativa en base a cuyo contraste nuestro orden político y cultural trata de definirse a sí mismo. El historiador Enzo Traverso llega a describir a la memoria del mismo como la religión civil de Occidente $^{5}$.

Por otro lado, el Holocausto explicita las tensiones que subyacen a las metodologías de investigación y escritura de la historia. Tanto en el plano relativo a la función social de estos discursos como mecanismos de cohesión social, como en relación a los problemas de extracción de información a través del diálogo con el testigo. Así, defenderemos a continuación cómo las características de este evento obligan a replantearnos la definición de la memoria colectiva y los presupuestos de su relación con el discurso histórico, tal y como las plantea Halbwachs.

\section{Maurice Halbwachs y la memoria colectiva}

Dada la ambigüedad y el carácter polémico del término, es preciso definir el concepto que tratamos. Maurice Halbwachs ofrece en Los marcos sociales de la memoria ${ }^{6}$ y en La memoria colectiva ${ }^{7}$ no sólo una caracterización, sino una justificación epistémica del uso sociológico de esta categoría, cuya idea central consiste en la reivindicación del carácter social de la actividad rememorativa individual.

Este concepto puede tener la apariencia de un oxímoron en la medida en que, en sentido estricto, son los individuos y no los colectivos, los sujetos de recuerdo. Presupone, consecuentemente, una abstracción que es preciso legitimar. Así, las bases para su uso derivan del condicionamiento o la influencia de los factores colectivos en el proceso rememorativo de cada individuo. Un condicionamiento que se da en dos niveles diferentes. En un plano narrativo - que afecta a la forma a través de la cual se presentan los recuerdos al sujeto - y en un plano relativo a los propios contenidos de la actividad mnémica.

En primer lugar, defiende Halbwachs, la memoria individual no es una memoria fotográfica consistente en la adición continua de imágenes del pasado. Al contrario, los recuerdos se presentan al individuo a través de cadenas con sentido, en torno a fenómenos investidos con un significado, que orientan el desencadenamiento de los mismos. Esa narratividad no depende únicamente de la autobiografía de cada individuo sino que se ve

4. Traverso, E.: "Memoria: la religión civil del Holocausto" en El final de la modernidad judía. Historia de un giro conservador, Valencia: Universidad de Valencia, 2003.

5. Halbwachs, M.: Los marcos sociales de la memoria, Barcelona: Antrhopos, 2008.

6. Halbwachs, M.: La memoria colectiva, Zaragoza: Prensas Universitarias de Zaragoza, 2008.

Thémata. Revista de Filosofía No56 (2017) pp.: 41-60. 
influenciada por factores colectivos, por las relaciones sociales en las que el individuo se encuentra envuelto.

En segundo lugar, Halbwachs plantea que, cuando un sujeto trata de reconstruir las vivencias de su pasado más remoto, llega a retomar contenidos mnémicos que él nunca ha llegado a percibir y que no forman parte de su experiencia personal, sino que son extraídos de los relatos colectivos vigentes. Cuando un individuo se remonta mnémicamente a largo plazo, se difuminan los límites entre sus vivencias y aquellos recuerdos construidos socialmente.

Estos dos planos conducen a Halbwachs a negar cualquier validez a la visión de una práctica rememorativa aislada de su contexto social. Veamos cómo lo plantea en una de sus obras:

Consideremos ahora la memoria individual. No está totalmente aislada y cerrada. Muchas veces, para evocar su propio pasado, un hombre necesita recurrir a los recuerdos de los demás. Se remite a puntos de referencia que existen fuera de él, fijados por la sociedad. Es más, el funcionamiento de la memoria individual no es posible sin estos instrumentos que son las palabras e ideas, que no ha inventado el individuo, sino que le vienen dados por su entorno. [...] nuestra memoria no se confunde con la de los demás. Está limitada de forma bastante rigurosa en el espacio y en el tiempo. La memoria colectiva también lo está: pero sus límites no son los mismos. [...] Llevo conmigo un bagaje de recuerdos históricos, que puede aumentar conversando o leyendo. Pero se trata de una memoria que he copiado y no es mía ${ }^{8}$.

Es decir, la memoria, además de una base neural, psíquica... requiere de una base social, que remite a las relaciones comunicativas de un grupo humano en un momento dado. La memoria colectiva sería ese conjunto de presupuestos, condicionantes y moduladores sociales de cada una de las memorias autobiográficas de los individuos. Es una forma de relación con el pasado inmediata, parcial, históricamente situada, condicionada afectivamente... Ahora bien, continúa Halbwachs, esta forma espontánea e impersonal de relación con eventos del pretérito, contrasta con el carácter distanciado e intencional de la escritura de la historia. Ya que esta última cuenta con una mediación posibilitada por la dimensión textual de su labor. Es decir, es precisamente la diferencia entre los soportes para la transmisión de los contenidos de la historia y la memoria colectiva, la que sirve de eje para establecer las diferencias entre ambas formas de interactuar con el pasado.

7. Ibid, p. 54 .

Thémata. Revista de Filosofía No56 (2017) pp.: 41-60. 


\section{La discontinuidad entre la memoria colectiva y el discur- so histórico}

No es de extrañar que se sitúe el origen de la historia en el nacimiento de la escritura y que se haya definido a las sociedades ágrafas como sociedades regidas por principios de la memoria colectiva. La dimensión textual de la escritura histórica implica tanto un nuevo soporte subjetivo -universalmente accesible y capaz de sobrevivir al paso del tiempo-, como un nuevo tipo de fuente histórica- el documento. Es la supervivencia diacrónica del texto escrito la que permite la pretensión de independencia del historiador respecto a las narraciones orales.

El propio Halbwachs, como metáfora, llega a establecer una contraposición entre dos tipos de memoria: la memoria viva - que no es sino la memoria colectiva que se reproduce dinámicamente a través de las relaciones sociales - y la memoria muerta, es decir, la historia. Desde el punto de vista de Halbwachs, la historia nace en el momento mismo en que la influencia de la tradición se limita, dejando un espacio para reconstruir una visión del pasado independiente del marco colectivo en el que está inmerso el historiador. La historiografía puede desarrollarse, por tanto, a partir de su ruptura con los marcos sociales de la memoria colectiva. Como vemos, Halbwach explota las diferencias en la relación de ambas categorías con el pasado.

Si bien las narraciones orales y todo el conjunto de relaciones sociales que dan consistencia y contenido a la memoria social, se agotan, se modifican, son substituidas, con el paso de las generaciones, la estabilidad que ofrece el texto escrito para la historia, da lugar a un desajuste temporal entre ambas categorías. Este desajuste hace posible el desarrollo del discurso histórico y marca sus diferencias. Veamos nuevamente como plantea esta cuestión Halbwachs:

Sucede que, en general, la historia comienza en el punto donde termina la tradición, momento en que se apaga o se descompone la memoria social. Mientras un recuerdo sigue vivo, es inútil fijarlo por escrito, ni siquiera fijarlo pura y simplemente. Asimismo, la necesidad de escribir la historia de un periodo, una sociedad, e incluso de una persona, no se despierta hasta que están demasiado alejados en el tiempo como para que podamos encontrar todavía alrededor durante bastante tiempo testigos que conserven algún recuerdo. Cuando la memoria de una serie de acontecimientos ya no se apoye en un grupo [...] el único medio de salvarlos es fijarlos por escrito en una narración continuada ya que, mientas que las palabras y los pensamientos mueren, los escritos permanecen ${ }^{9}$.

8. Ibid, p. 80.

Thémata. Revista de Filosofía No56 (2017) pp.: 41-60. 
La historia se caracteriza a través de sus relaciones diacrónicas con el pasado mientras la memoria carece de las mismas y sólo posee una dimensión sincrónica. Es meramente una corriente de pensamiento vivo, que se reproduce de forma espontánea a través de la evolución de los grupos humanos, carente de los artificios metodológicos de los que hace uso el historiador, e incapaz de trascender sus condicionamientos más allá de los límites del grupo. En el fondo Halbwachs, con esta definición de la memoria colectiva, la está superponiendo con el campo de la historia oral. Es la memoria que se mantiene viva a través de la comunicación, de las relaciones sociales que se reproducen día a día. Está limitada a un espacio social formado por únicamente tres generaciones: los hijos, los padres y los abuelos. Cualquier contenido mnémico que exceda el límite de coexistencia formado por estas tres generaciones, es identificado inmediatamente con un elemento que forma parte del discurso histórico.

En definitiva, parece concluir Maurice Halbwachs, al rememorar nunca salimos de un núcleo temporal delimitado y al escribir la historia estamos obligados a trascenderlo. La rememoración se define espacialmente, en relación a la sociedad en que se sitúa esta actividad, y la historización temporalmente.

Aunque la obra de Maurice Halbwachs finalizó con su defunción en la segunda guerra mundial, algunos autores han desarrollado ideas congruentes con este modelo. Es decir, con la caracterización antinómica de la memoria colectiva y el discurso histórico. Vamos a tratar las tesis de dos de estos autores con el objetivo de terminar de conformar este marco teórico.

Abordemos las ideas de Pierre Nora, historiador francés de la segunda mitad del siglo XX. Su obra más conocida consiste en una reconstrucción de los emblemas de la memoria ${ }^{10}$ de la Francia de la época, que contiene una serie de tesis acerca de las relaciones entre las dos categorías con las que tratamos. Desde su óptica, la memoria colectiva y la historia comparten un mismo contenido - el pasado en su relación con el presente - pero se sostienen sobre principios y reglas diferentes. Principios que les conducen a posicionarse en una situación de crítica recíproca.

Pierre Nora parte de un hecho empírico constatable en algunas prácticas culturales de nuestro tiempo. Un fenómeno que ha sido categorizado por algunos autores -como Jay Winter ${ }^{11}$ - como el estallido de la memoria. En el contexto de los años posteriores a las dos guerras mun-

9. Nora, P. (1984): Pierre Nora en Les liéux de mémoire, Paris: Trilce, 2008.

10. Winter, Jay. "The generation of memory: Reflections on the "Memory boom" en contemporary historical studies", Archives \& Social Studies: A Journal of Interdisciplinary Research, Vol. 1, no. 0 ,March 2007.

Thémata. Revista de Filosofía №56 (2017) pp.: 41-60. 
diales se reproducen con mayor frecuencias prácticas de creación de objetos materiales con cierta carga rememorativa: museos, monumentos... Objetos investidos de un contenido semántico derivado de su relación con un fenómeno muy significativo para la memoria colectiva de la época. No obstante, esta obsesión por la memoria no constituye para Pierre Nora sino un síntoma de una crisis y agotamiento de la memoria colectiva. Crisis que constituye una condición indispensable para la evolución de la historiografía, que nuevamente será definida en función de su autonomía respecto a los condicionamientos de la memoria colectiva.

Desde su punto de vista, si bien es cierto que durante un período de tiempo la memoria y la historia coexistieron en cierto equilibrio, finalmente una serie de sucesos históricos provocaron la ruptura de esa unidad originaria, así como una crisis en las sociedades tradicionales. Desde la óptica de Nora, el proceso de secularización y aceleración de la historia dio lugar a la incapacidad de la memoria colectiva a la hora de influenciar y determinar las prácticas y los comportamientos de los grupos humanos. El surgimiento y autonomía de la historia está ligado a la desaparición de las sociedades arcaicas regidas por el espacio de experiencia ${ }^{12}$, que permite el establecimiento de una distancia con el pasado.

La memoria está tan presente en nuestro contexto cultural porque, en cierto sentido, ya no hay memoria. La presencia del pasado transmitido oralmente y con un potencial normativo queda progresivamente deslegitimada. La abundancia de los lugares de memoria no es más, por tanto, que un síntoma de cierta nostalgia provocada por el trauma de la aceleración de los tiempos modernos, que no hace sino certificar el acta de defunción de la memoria colectiva en las sociedades contemporáneas.

Siguiendo esta línea argumentativa, es especialmente significativa la obra del historiador hebreo Yosef Hayim Yerushalmi, que, en Zajor ${ }^{13}$, llama la atención sobre los cambios en la conciencia cultural del pueblo judío, a través de las ambivalentes relaciones que se fueron articulando entre la memoria y la historiografía. Lo peculiar de este autor es que percibimos cierta consonancia entre su lectura de la crisis de la memoria del pueblo hebreo y las tesis desarrolladas por Pierre Nora. Como si la evolución del pueblo judío fuera un caso radicalizado de ese movimiento.

La identidad del judaísmo se ha construido parcialmente en base al esfuerzo tácito por recordar las tribulaciones y sufrimientos de sus ancestros. Ahora bien, analiza Yerushalmi, la evolución de la historiografía

11. Categoría que tiene su origen en Kosselleck, R.: "'Espacio de experiencia" y "Horizonte de expectativa" en Futuro-pasado: Para una semántica de los tiempos históricos, Barcelona: Paidós, 1993, pp, 333-358.

12. Yerushalmi, Y. H. Zajor. La historia judía y la memoria judía, Barcelona: Anthropos, 2002.

Thémata. Revista de Filosofía Nº56 (2017) pp.: 41-60. 
judía ha implicado un doble proceso: La atrofia de la memoria y la hipertrofia de la historia. Los historiadores sólo pueden llevar a cabo su labor a través de su divorcio con los intensos lazos de pertenencia que perpetúa la memoria colectiva judía; lo que inaugura, a su juicio, un proceso de decadencia de aquella y de progresiva desmitificación de las entidades y significados colectivos. Este fenómeno, necesario para la reconstrucción objetiva de la historia de Israel, no deja de ser lamentado en relación a las consecuencias que trae consigo para su cohesión identitaria. Ya que la distancia diacrónica que implica la historiografía es incapaz de suplantar las funciones que ejercía su contraparte. En este sentido, nada puede reemplazar la fe mesiánica del pueblo judío. La secularización de sus formas de acceso al pasado implica el debilitamiento de sus rasgos de identidad.

\section{La historia y la memoria a través del Holocausto}

Podemos resumir la tesis que legitima el modelo teórico anteriormente desarrollado de la siguiente forma: es el desacoplamiento temporal entre la memoria y la historia, derivado de la diferencia entre el espacio sincrónico en el que habita la primera y el diacrónico en el que se desarrolla la segunda, entre la limitación de la primera a las condiciones espacio-temporales del grupo y la pervivencia en el tiempo que ofrece la escritura para la segunda, el que justifica su caracterización antinómica, es decir, la legitimación de la presencia de un hiato entre ambas. Frente a este planteamiento, propondremos las siguientes críticas a partir del análisis de los desafíos que el Holocausto presenta a la representación histórica.

En primer lugar, defenderé que la importancia que adquiere el testigo como fuente de conocimiento del holocausto y las peculiaridades de esta figura, cuestionan las propiedades antinómicas anteriormente atribuidas a historia y memoria. Características que partían del contraste entre la dimensión textual de la primera y el soporte oral de la segunda

En segundo lugar, argumentaré que la pervivencia de la herida traumática del Holocausto más allá de los límites de los grupos humanos en el que se produjo la recepción del evento, problematiza la limitación de la memoria colectiva a las condiciones espacio-temporales del grupo. También cuestiona la supuesta autonomía de la historia cuando se abstrae de los marcos sociales de la memoria.

Finalmente, frente a la contraposición entre el carácter constatativo de la historia, derivado de la adecuación de las proposiciones de sus textos a los hechos del pasado, y el carácter performativo de la memoria, derivado de su potencial para fortalecer la cohesión social, el caso del Holocausto pone de relieve la relevancia de la escritura del pasado del historiador, en relación a la 
posibilidad de construir una nueva cohesión social nacional en la postguerra. Las consecuencias prácticas subyacentes a las diferentes posiciones en el debate de los historiadores dan cuenta de estas dificultades.

\subsection{El testigo en la encrucijada entre la historia y la memoria}

Una de las características fundamentales de la historiografía del Holocausto es el recurso al registro de las memorias autobiográficas de los agentes históricos que vivieron aquellos acontecimientos. Varios autores han caracterizado al pasado siglo como la era del testimonio, en relación a la relevancia política, jurídica, epistémica y social de esta figura. Como hemos desarrollado, el modelo que criticamos se sostiene sobre la separación entre la historia y la memoria a partir de la distinción entre sus soportes, escrito y oral, respectivamente. Según este modelo, el testimonio sólo tendría valor histórico a partir de su trama en el medio escrito, a través de la labor de un historiador que purgue su visión del pasado de elementos subjetivos, en la medida de lo posible. En el ámbito del testimonio y de la historia oral, se ponen en juego las relaciones entre las categorías con las que tratamos. Situación que se radicaliza ante un fenómeno como el Holocausto, debido a la idiosincrasia del superviviente como fuente de información.

Paul Ricoeur defendía en su obra La memoria, la historia, el olvi$d o^{14}$, que el testigo se encuentra en el lugar de transición entre la memoria colectiva y el discurso histórico. No obstante, debemos añadir un complemento. Cuando nos referimos a esta figura no designamos a un testigo en el sentido de un tercero que da cuenta de los hechos que ha visto de forma independiente. El testigo del holocausto es un superviviente ${ }^{15}$, una víctima, y esta condición redefine todas las propiedades de su relectura del pasado y su anclaje entre las categorías que tratamos. En primer lugar, porque su exposición de los hechos será radicalmente parcial. Pero fundamentalmente en la medida en que el contenido semántico que rodea a esta figura reconfigura sus relaciones con el historiador.

En este apartado nos vamos a limitar a destacar las dinámicas que subyacen a las relaciones entre el historiador y el testigo, entre el entrevistador y el entrevistado, para cuestionar las pretensiones de independencia

13. Ricoeur, P.: La memoria, la historia, el olvido. Madrid: Trotta, 2003, p. 208.

14. Es muy significativa, en este contexto, la distinción que, en base a la etimología latina, establece Giorgio Agamben entre el testigo como "testis" - aquel que sirve de tercero, de agente externo en un litigio judicial - y como "superstes" - aquel que ha atravesado la totalidad de un acontecimiento y ofrece un testimonio desde la radical parcialidad de su condición de superviviente - en Agamben, G.: Homo saccer III. Lo que queda de Auschwitz. El archivo y el testigo, Valencia: Pre-textos, 2014, p. 15.

Thémata. Revista de Filosofía No56 (2017) pp.: 41-60. 
del primero. Debemos considerar que, en primera instancia, en la propia historiografía del Holocausto, la radical parcialidad de estas fuentes de información implicó una actitud crítica y distanciada por parte de los historiadores, que intentaban adecuarlos a los esquemas de su objeto tradicional de conocimiento: el documento.

Podemos leer la tentativa de tratar al testigo como un documento viviente, como un esfuerzo para mantener la distancia y epistémica y emocional con aquel. El objetivo era el de asegurar la autonomía del discurso histórico a partir de su aislamiento con elementos distorsionadores, cuyo origen se encuentra en la memoria colectiva de un grupo humano. Nuestro argumento se dirigirá, consecuentemente, a mostrar cómo las dinámicas subyacentes a la relación entre el testigo y el historiador, cuando se enfrentan a las memorias de un hecho traumático, inhabilita estas pretensiones de distanciamiento. Para tal fin vamos a apoyarnos en la experiencia con testigos del Holocaustos, de la que da cuenta Dori Laub en sus ensayos ${ }^{16}$.

Laub nos ofrece una presentación de este problema que enfatiza la imposibilidad de establecer una separación entre el historiador y el superviviente, en la medida en que el proceso de extracción de la información, al requerir datos vinculados a experiencias traumáticas reprimidas por el testigo, exige del entrevistador una actitud activa que le lleva a experimentar él mismo las vivencias testimoniadas. Esta última tesis, la conversión del historiador de mero interlocutor a testigo de las propias vivencias narradas, es especialmente polémica. No deja de ser significativo que Dori Laub, además de psicoanalista de testigos del Holocausto, sea ella misma una superviviente de la Shoah. Desde su óptica, la inmersión del historiador en el acto del testimonio deriva de lo que ella denomina "los peligros de la escucha". La transgresión moral sufrida por la víctima, la inmediatez espacial con ella, la sincronía temporal con los eventos narrados y el hecho de que la entrevista pone sobre la mesa cuestiones que para el historiador no dejan de ser significativas, imposibilitan la reducción del testigo a la condición de documento viviente. Veamos cómo describe Dori Laub esta condición:

Para el oyente que entra en contacto con el testimonio, una jornada con peligros le espera. Hay peligros en la escucha del trauma. El trauma - y sus impactos en el oyente - no deja ningún lugar intacto. En el momento en el que conoce al superviviente, se conoce a sí mismo realmente; y esa no es una tarea simple. La experiencia del

15. Laub, D.: "An Event without a Witness: Truth, Testimony and Survival" en Felman, S. y Laub,D.: Testimony. Crisis of witnessing in literature, psychoanalysis, and history, New York and London: Routledge, pp, 75-92, 1992. 


\section{Las discontinuidades entre la memoria colectiva y la historia: Una crítica a partir de la experiencia del Holocausto}

superviviente, o la experiencia del Holocausto, es una versión condensada de aquello que trata la vida: contiene muchas cuestiones existenciales que somos capaces de evitar en nuestra vida diaria. Durante la experiencia del Holocausto y, de ahora en adelante, durante la inevitable confrontación con estas cuestiones, el oyente no puede ignorar el problema de enfrentarse a la muerte; de enfrentarse al tiempo y a su paso; del significado y propósito de la vida, de las límites de la propia omnipotencia; de la pérdida de aquellos que están cerca de nosotros; la gran cuestión de nuestra soledad última [...] y así... ${ }^{17}$.

De esta forma, esta relación con el superviviente implica la absorción de los contenidos afectivos que rodean al mismo, por parte del historiador. Contenidos que influirán en el proceso de escritura de la historia. Dicha presencia se traduce en el desarrollo de una tendencia a establecer una identidad empática con las víctimas, que a su vez deriva en la inclinación a construir una visión del pasado desde la óptica de esta figura histórica. Tal y como defiende Dominick LaCapra ${ }^{18}$, la empatía con las víctimas no constituye un obstáculo o una enmienda a la totalidad respecto a estas representaciones del pasado, al inhabilitar su objetividad. Al contrario, es una constante cuando, enmarcados en el ámbito de la historia del presen$t e^{19}$, tratamos de historizar eventos investidos de fantasías catastróficas. No hay, en cierto sentido, método de cura para superar la relación transferencial con esta fuente de conocimiento histórico.

El testigo y la empatía que con él mantiene el historiador, empapan al discurso histórico de los contenidos de la memoria colectiva de ese contexto. Ahora bien, las dinámicas subyacentes a esta particular relación con el testigo no se agotan en el espacio en el que hay una coexistencia temporal entre el historiador y esta figura. Es decir, no se limita a la historia del presente. Al contrario, la empatía con las víctimas tiene una transmisión cultural más allá de ese espacio, a través de las formas simbólicas que constituyen el soporte de estos contenidos. Abordar la transmisión cultural de los contenidos mnémicos más allá del grupo humano desde el que se produce la recepción de los eventos, nos obliga a introducirnos en nuestro segundo argumento.

16. Ibid, p. 72. Tanto la traducción de esta cita, como la del resto que proceden de obras en inglés, son mías.

17. LaCapra, D.: Escribir la historia, escribir el trauma. Buenos Aires: Nueva Visión, 2005, p, 65.

18. Es posible delimitar este concepto en función de las categorías con las que tratamos. Esta disciplina se dedica al estudio de los procesos de trama histórica de aquellos eventos que tienen algún tipo de pervivencia en la memoria viva de una generación contemporánea al proceso mismo de escritura de la historia.

Thémata. Revista de Filosofía No56 (2017) pp.: 41-60. 


\subsection{La dimensión cultural de la memoria de la Shoah}

Este argumento se dirige a cuestionar el contraste entre la limitación de la memoria colectiva al espacio de tres generaciones - hijos, padres y abuelos - y la estabilidad del discurso histórico a través del paso del tiempo. Como hemos visto, la recepción histórica del Holocausto nos sitúa en un ámbito en el que dicho desacoplamiento temporal no se ha producido. Es decir, en una situación historiográfica caracterizadas por la ausencia de una distancia espacial y temporal con el fenómeno en cuestión.

En este sentido, resulta paradigmático el caso de la crítica del historiador alemán Ernst Nolte a la supuesta singularidad del Holocausto nazi, desarrollada en su ensayo "El pasado que no pasa" ${ }^{20}$, publicado en 1986. Nolte defiende la necesidad de superar algunas tendencias historiográficas de la época en relación a la Shoah, en la medida en que interpreta que han quedado subordinadas acríticamente a la sublimación de esta experiencia histórica. La conversión del Holocausto en un mito negativo - proceso que desde su óptica es artificial - debe ser contrarrestada por la introducción de este fenómeno en una cadena causal a gran escala que le aplique los mismos estándares historiográficos de los que se hace uso para tramar el resto de eventos. Sólo así se aseguraría la independencia de la historiografía respecto a factores políticos, sociales, culturales... que tienen su origen en la memoria colectiva de la época. Por lo tanto, considero que la reivindicación noltiana de recuperación de la autonomía de la historia respecto al peso abrumador de la memoria del Holocausto, puede ser leída como el intento de que se produzca ese desacoplamiento temporal entre memoria e historia, que detenga la influencia de la primera sobre la segunda.

Ahora bien, si atendemos a la evolución de la memoria del Holocausto, tomamos consciencia de que, aunque desde nuestro particular horizonte histórico, la Shoah no forma parte de la historia del presente, no es cierto que el peso del trauma respecto a tales eventos haya desaparecido o haya perdido totalmente su influencia sobre la disciplina historiográfica.

En el siglo XXI nos encontramos más allá del espacio de coexistencia generacional de aquellos que viven esos eventos. No queda prácticamente ningún testigo vivo de los mismos, pero aun así no podemos hablar del debilitamiento de esta memoria. En cierto sentido, defenderemos, la memoria traumática de Auschwitz no desaparecerá con la muerte del último superviviente, ni con la de la generación que lo vivió, ni con aquella formada por los nietos de esa generación. Esta condición nos conduce a

19. Nolte, E.: "The Past That Will Not Pass: A Speech That Could Be Written but Not Delivered", en Knowlton, J. y Cates, T. (eds.): Forever in the Shadow of Hitler?, New Jersey: Humanities Press, 1993, pp. 18-24.

Thémata. Revista de Filosofía №56 (2017) pp.: 41-60. 
constatar la pervivencia y evolución de elementos de la memoria colectiva más allá de los límites concretos del grupo desde el que se produce la recepción de este evento. Por este motivo resulta cuestionable tanto la limitación de la memoria colectiva a un espacio sincrónico, como la consecuente autonomía de la historia una vez que logra trascender al mismo. La imposibilidad de aplicar a la evolución historiográfica de este fenómeno el modelo de Halbwachs, deriva de su caracterización de la memoria colectiva en términos puramente sociales, situando su contexto en un espacio de coexistencia entre tres generaciones. El sociólogo francés acierta al señalar la base social de toda actividad rememorativa pero su sistema falla al limitarse este plano. Para poder dar cuenta de estas dificultades es necesario mantener que la memoria, además de una dimensión psíquica y social, posee una dimensión cultural, que da cuenta de la evolución de sus contenidos a lo largo del tiempo.

En este sentido es muy significativo el diálogo que mantienen con la postura de Halbwachs, Jan Assmann y Aleida Assmann; especialistas en historia de las religiones y en teoría cultural, respectivamente. Ambos tratan de complementar las tesis del sociólogo francés. Desde su punto de vista, cuando estudiamos los condicionantes y moduladores colectivos de los procesos individuales de rememoración, debemos establecer una distinción entre la memoria comunicativa y la memoria cultural. El límite entre ambas se sitúa a partir de su capacidad para trascender la frontera del grupo humano en cuestión.

Según Jan y Aleida Assmann, la memoria comunicativa se identifica y superpone con la memoria colectiva de Halbwachs, es la memoria que se sostiene a través de las relaciones sociales de un grupo humano a lo largo de su día a día. La memoria cultural se caracteriza, en cambio, de forma completamente antagónica:

De la misma forma en que la memoria comunicativa es caracterizada por su proximidad a las relaciones del día a día, la memoria cultural es caracterizada por su distancia a esas relaciones. La distancia respecto al día a día (trascendencia) marca su horizonte temporal. La memoria cultural tiene sus puntos de referencia; sus horizontes no cambian con el paso del tiempo. Estos puntos de referencia son eventos del pasado, cuya memoria se mantiene a través de las formaciones culturales (textos, ritos, monumentos) y comunicaciones institucionales (recitación, práctica, observación) [...] En el fluir de las comunicaciones diarias estos festivales, ritos, poemas, imágenes, etc. ${ }^{21}$.

20. Assmann, J. "Collective memory and cultural identity" en New German Critique No. 65, Cultural History/Cultural Studies (Spring - Summer, 1995), pp. 125-133, p. 129.

Thémata. Revista de Filosofía ํ56 (2017) pp.: 41-60. 
La memoria cultural se define como el producto de un proceso de almacenamiento, exteriorización e institucionalización de los contenidos que se desarrollan en la memoria comunicativa, a través de las formas simbólicas con las que cuenta ese grupo humano. Entre estas formas incluimos tanto prácticas culturales, como monumentos, como textos canónicos, que revelan hasta qué punto la labor de la escritura no se limita al ámbito del discurso histórico.

Las dinámicas de los grupos humanos van generando un almacén inmenso de contenidos mnémicos. De forma que cada una de aquellas será operativa en un contexto concreto, en función de una serie de condiciones. Para determinar cuáles de esos elementos son operativos en cada contexto, Aleida Assmann establece una distinción entre el canon y el archivo ${ }^{22}$.

El canon abarca aquellos contenidos cuya presentación trae consigo implicaciones normativas. Refieren a los elementos de la memoria que deben ser recordados, leídos, citados como autoridad, reproducidos en diferentes prácticas... El archivo, al contrario, designa a los contenidos que con el paso del tiempo han sido desechados y excluidos, pero que tienen la suficiente relevancia histórica para ser almacenados en forma material.

Como observamos, el carácter cultural y diacrónico de la memoria colectiva no sólo contiene un potencial explicativo para dar cuenta de la pervivencia del trauma del Holocausto más allá del espacio de recepción de los eventos. También da cuenta de la imposibilidad de sostener la autonomía de la historia, en la medida en que refuta el argumento básico de este modelo. Según aquel, sólo cuando el recuerdo desaparece de la memoria colectiva puede ser tramado en el texto escrito por parte de un historiador. Ahora bien, la dimensión cultural y diacrónica de la memoria, implica que no se produce desolapamiento alguno entre memoria e historia. Su superposición no se limita a la historia del presente, sino que es coextensiva a la evolución de la historiografía. El carácter diacrónico de la memoria hace que se perpetúe a lo largo del tiempo, por lo que la caracterización antinómica de la relación entre las categorías que tratamos pierde fuerza argumentativa.

21. Assmann, A. "Re-framing memory. Between individual and collective forms of constructing the past" en Tilmans, K., Van Vree, F. y Winter, J. (eds): Performing the Past, Amsterdam: Amsterdam University Press, 2010, pp. 35-50, p. 41. 


\subsection{El potencial performativo del discurso histórico}

En este apartado el objetivo es partir del análisis de las polémicas generadas por la utilización del capital semántico derivado del Holocausto en el Historikerskreit ${ }^{23}$, con el fin de examinar hasta qué punto las voces y los silencios de la memoria permiten entender las voces y los silencios de la historia; situación que constituiría, a su vez, un síntoma respecto a las deficiencias del modelo que criticamos. El debate de los historiadores alemanes es un caso significativo, en la medida en que consiste en una discusión teórica que escondía de fondo cuestiones prácticas y que revelaba hasta qué punto la visión del pasado que ofrece el historiador tiene un potencial de cohesión social.

El debate sobre la singularidad del Holocausto no versa, pese a su apariencia, acerca de la cuestión de si la Shoah fue un evento único o si es posible establecer comparaciones históricas con otros fenómenos. $\mathrm{Al}$ fin y al cabo, esta discusión sería fácilmente reductible a una perogrullada. En cierto sentido, el Holocausto es un fenómeno único, en la medida en que todo acontecimiento histórico cuenta con una serie de propiedades específicas. Por otro lado, también sería comprable, ya que la comprensión histórica requiere el establecimiento de taxonomías que se sostienen sobre la presencia de elementos comunes entre los eventos. Al contrario, el problema que se dirime en el debate es más bien si negar la radical singularidad del Holocausto, como fenómeno que refleja el amplio espectro de una cultura, y someterlo al análisis histórico tradicional, es una tarea legítima y axiológicamente neutral. $\mathrm{O}$ si, en cambio, es posible detectar ciertas tendencias ideológicas en estos procesos de reconstrucción histórica, que deslegitiman el proyecto.

A este proceso de revisión de la historia oficial del Holocausto, que ponen en marcha historiadores como Ernst Nolte, Michael Stürmer, Klaus Hildebrand o Andreas Hillgruberg, subyacen dos tipos de motivaciones. En primera instancia, un razonamiento de tipo epistemológico ya citado. Para garantizar la objetividad de la historiografía alemana es necesario superar la inhibición que constituye el trauma del Holocausto para la memoria pública y el ámbito historiográfico. Ahora bien, también es posible percibir un interés práctico vinculado a la posibilidad de establecer una identidad nacional unificadora en la postguerra. Al fin y al cabo, existirían enormes dificultades a la hora de fundamentar el patriotismo alemán atendiendo a la caracterización imperante de aquellos eventos. ¿Cómo justificar de forma legítima la fidelidad a la patria cuando su historia estaba

22. Knowlton, J. y Cates, T. (eds.): Forever in the Shadow of Hitler?, New Jersey: Humanities Press, 1993.

Thémata. Revista de Filosofía Nº56 (2017) pp.: 41-60. 
contaminada por la transgresión moral derivada de aquellos sucesos? El tratamiento de la Shoah como un acontecimiento extremo e irreductible al análisis histórico, implica la presencia de una discontinuidad fundamental a lo largo de la historia alemana. El siguiente párrafo de Strümer refleja esta preocupación:

En un país sin memoria cualquier cosas es posible. Los investigadores avisan de que entre las ciudades industrializadas de la República Federal hay una enorme falta de comunicación entre generaciones, un escaso sentido de auto-confianza entre su gente, y una enorme variación de valores. ¿Cómo verán los alemanes su propio país, Occidente o a ellos mismos, mañana? Uno puede asumir que habrá algún tipo de continuidad en la comprensión alemana de su propio país. Pero no puede estar seguro. ${ }^{24}$

Consecuentemente, estos historiadores dan inicio a una serie de revisiones históricas de este evento. Situándose en las antípodas del Hier Ist Kein Warum de Claude Lanzmann, tratan de agotar sus causas y factores. Algunas de sus obras fueron especialmente polémicas en relación al lugar en que situaban la responsabilidad del pueblo germano respecto a aquellos acontecimientos. Es decir, a partir de la compleja conexión existente entre explicación histórica en base a causas, y responsabilidad colectiva.

Vamos a describir brevemente los rasgos de la historia de la Shoah por parte de Nolte, en la medida en que es aquella que mejor refleja todas estas tensiones y problemas. Desde su punto de vista, el Holocausto, y el surgimiento del régimen nazi, sólo pueden tener lugar a partir de un movimiento de oposición y resistencia nacionalista respecto al proceso de desaparición de las tradiciones y a la consecuente sensación de anomía que sufre el sujeto moderno. El proyecto del nacionalismo alemán sólo tiene sentido como respuesta ante la lucha por la autonomía que está asociada a la modernidad y cuya mayor implementación histórica sería el marxismo soviético. Esta última es la tesis central de Nolte ${ }^{25}$. Considera que el genocidio judío constituye una respuesta derivada del miedo al gulaj soviético. Ernst Nolte llega a definir al Holocausto como una acción asiática que emula el genocidio soviético y cuya única novedad consiste en la inno-

23. Stürmer, M.: "History in a Land without History" en Knowlton, J. y Cates, T. (eds.): Forever in the Shadow of Hitler?, cit, pp. 18-24, p. 16.

24. Ernst, N.: "Beween Historical Legend and Revisionism? The Third Reich in the Perspective of 1980"en J. y Cates, T. (eds.): Forever in the Shadow of Hitler?, cit, pp.1-16.

Thémata. Revista de Filosofía №56 (2017) pp.: 41-60. 
vación técnica de las cámaras de gas. Esta interpretación se sitúa en las antípodas de la tesis sobre la singularidad del Holocausto.

El disenso entre los historiadores explotó debido a los argumentos de Jürgen Habermas ${ }^{26}$. El filósofo alemán acusó la falta de coherencia y la distorsión del pasado que operaba en las obras de los revisionistas. Interpretó que estaban motivadas por la existencia de ciertas tendencias apologéticas, en las que se trataba de eludir la carga que imprime el genocidio en la memoria de la época, debido a fines prácticos. En concreto, a la tentativa de impulsos conservadores dirigidos a rebajar la relevancia y el peso de aquellos acontecimientos para hacer posible un patriotismo tradicionalista como seña de identidad en la Alemania de la post-guerra. Detrás de unos estudios históricos que se presentan a sí mismos como objetivos, se encuentra el esfuerzo por construir un contramito, un mito positivo sobre la honorable historia nacional a largo plazo que compense la deshonorable historia del III Reich.

Frente a este proyecto revisionista, Habermas defiende la singularidad de este evento en base a la necesidad política de integrar a Alemania en el orden internacional. Es decir, sólo si tomamos a la Shoah bajo esta condición, con toda su radicalidad, será posible construir una identidad cultural alemana en la postguerra.

Ambos participantes, como es fácil observar, tiene objetivos políticos en liza cuando proponen sus relecturas históricas. Condición que llama la atención respecto a la injerencia de los contenidos mnémicos en los proceso de escritura de la historia.

\section{Conclusión. Hacia una interacción entre la memoria colectiva y el discurso histórico}

Los tres argumentos anteriormente desarrollados tenían como eje la intención de revelar la influencia necesaria de los contenidos de la memoria colectiva en los procesos de escritura de la historia del pasado siglo. El fin era el de defender que estas injerencias no son excepciones limitadas al campo de la historia del presente, sino que son constantes en la evolución temporal de la historiografía. Así, pudimos mostrar las limitaciones de las tesis de Halbwachs, Nora y Yerushalmi en relación al problema que nos atañe.

Ahora bien, este proceso requiere de un complemento, consistente en la articulación de un movimiento opuesto: destacar la función del dis-

25. Habermas, J.: "Una gestión de daños. Las tendencias apologéticas en la historiografía alemana" en Habermas, J., Nolte E., y Mann, T.: Hermano Hitler, México: Herder, 2012.

Thémata. Revista de Filosofía No56 (2017) pp.: 41-60. 
curso histórico como mediador y modulador de los contenidos de la memoria colectiva. Siguiendo las tesis de Jan Assmann y Aleida Assmann, la memoria cultural constituye un enorme almacén cuyos contenidos se remontan a etapas previas de nuestra historia. Ahora bien, la determinación de cuáles de esos contenidos forman parte del archivo y parte del canon, cuáles operan de forma efectiva en los procesos rememorativos individuales y cuáles son olvidados en el almacén, depende de factores mediadores, de mecanismos de transición entre aquella frontera.

Entre estos factores tiene un lugar privilegiado el texto histórico, pues constituye la versión oficial de los acontecimientos del pasado que es interiorizada por muchos individuos. De forma que orienta y regula los contenidos de la memoria colectiva y las prácticas asociadas a la misma. La legitimidad social del discurso histórico y la tendencia del historiador a arrogarse el monopolio a la hora de definir y describir el pasado, explican la función mnémica del relato histórico. Al fin y al cabo, el texto histórico constituye una de las formas simbólicas - junto a los rituales y a los monumentos - que posibilita y modula la transmisión diacrónica de los contenidos de la memoria.

El potencial del discurso histórico para construir el anclaje identitario en la Alemania de la postguerra, desarrollado en el tercer capítulo, da cuenta de esta condición. La diferencia entre hacer de la Shoah el eje de la reconstrucción de la historia alemana o un evento más en la catastrófica historia del siglo XX, tiene consecuencias en el plano de la conformación de la memoria colectiva de la época.

Consecuentemente, estas tesis nos conducen a redefinir las relaciones entre la memoria colectiva y el discurso histórico, pues ambas no se caracterizan por sus discontinuidades o por su oposición recíproca, sino por sus interacciones y dependencias mutuas. La construcción del texto histórico es estructuralmente dependiente de los contenidos de la memoria común del grupo en cuyo seno se encuentra el historiador. Pero ese mismo documento, a su vez, influye, entre otros factores, en la conformación de los contenidos culturales de esa memoria. Las fronteras entre ambas, consecuentemente, se vuelven borrosas y porosas. La historia y la memoria se caracterizan por mantener una relación dialéctica, es decir, de influencia recíproca, en la que los contenidos de una no pueden definirse al margen de los de la otra. Sólo bajo este prisma podemos hacer inteligibles muchos de los conflictos historiográficos del pasado siglo, caracterizados por las 
tensiones existentes entre los procesos de reconstrucción del pasado y diferentes factores éticos, culturales y políticos.

\section{Bibliografía}

Assmann, A. "Re-framing memory. Between individual and collective forms of constructing the past" en Tilmans, K., Van Vree, F. y Winter, J. (eds): Performing the Past, Amsterdam: Amsterdam University Press, 2010, pp. 35-50.

Assmann, A.: Introduction to cultural studies: Topics, concepts, issues, Berlin: Erich Schmidt Verlag, 2012.

Assmann, J.: "Collective memory and cultural identity" en New German Critique No. 65, Cultural History/Cultural Studies (Spring Summer, 1995), pp. 125-133.

Assmann, J.: Religión y memoria cultural, Buenos Aires: Lilmod, 2008.

Habermas, J.: "Una gestión de daños. Las tendencias apologéticas en la historiografía alemana" en Habermas, J., Nolte E., y Mann, T.: Hermano Hitler, México: Herder, 2012.

Halbwachs, M.: La memoria colectiva, Zaragoza: Prensas Universitarias de Zaragoza, 2008.

Halbwachs, M.: Los marcos sociales de la memoria, Barcelona: Antrhopos, 2008.

Knowlton, J. y Cates, T. (eds.): Forever in the Shadow of Hitler? New Jersey: Humanities Press, 1993.

Kosselleck, R.: Futuro-pasado: Para una semántica de los tiempos históricos, Barcelona: Paidós, 1993.

LaCapra, D:. Escribir la historia, escribir el trauma. Buenos Aires: Nueva Visión, 2005.

LaCapra, D.: Representar el Holocausto, Buenos Aires: Prometeo libros, 2008.

Laub, D.: "Bearing Witness or the Viccisitudes of Listening" en Felman, S. y Laub,D.: Testimony. Crisis of witnessing in literature, psychoanalysis, and history, New York and London: Routledge, pp, 57-74, 1992.

Laub, D.: "An Event without a Witness: Truth, Testimony and Survival” en Felman, S. y Laub,D.: Testimony. Crisis of witnessing in literature, psychoanalysis, and history, New York and London: Routledge, pp, 75-92, 1992.

Nora, P. (1984): Pierre Nora en Les liéux de mémoire, Paris: Trilce, 2008.

Ricoeur, P.: La memoria, la historia, el olvido. Madrid: Trotta, 2003.

Traverso, E.: El final de la modernidad judía. Historia de un giro conservador, Valencia: Universidad de Valencia, 2003. 
Traverso, E.: El pasado, instrucciones de uso: historia, memoria, politica, Madrid: Marcel Pons, 2007.

Wieviorka, A.: The era of the witness, Ithaca and London: Cornell University Press, 2006.

Winter, J.: Remembering War, New Haven \& London: Yale University Press, 2006.

Winter, Jay. "The generation of memory: Reflections on the "Memory boom" en contemporary historical studies" en Archives \& Social Studies: A Journal of Interdisciplinary Research, Vol. 1, no. 0 ,March 2007.

Yerushalmi, Y. H. Zajor. La historia judia y la memoria judia, Barcelona: Anthropos, 2002. 